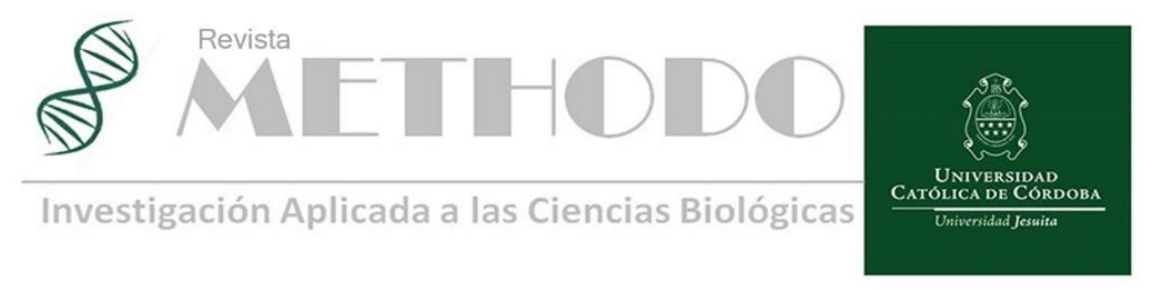

SEMBLANZA Rev. Methodo 2021;6(2):109-110

https://doi.org/10.22529/me.2021.6(2)09

Recibido 02 Mar. 2021 | Publicado 08 Abr. 2021

\title{
Padre César Azúa sj (1918-1992)
}

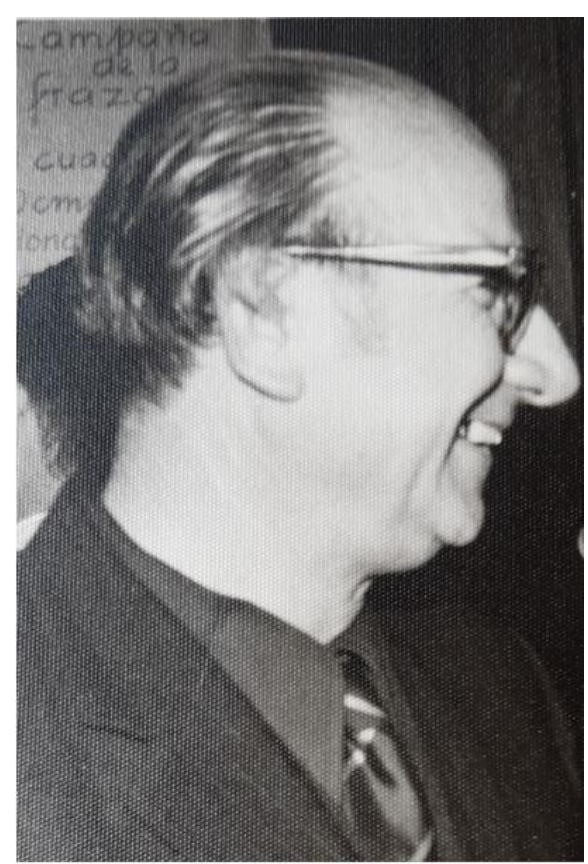

Figura 1. Padre. César Azúa S.J.

\section{Homenaje al Padre César Azúa sj}

Desde la reflexión que enseñaste cuantificamos la enorme riqueza que nos legaras: la fe y la fe en los jóvenes que fueron siempre su centro de preocupación y en esa preocupación estuvo siempre la formación de médicos y médicas que supieran servir a los demás: viendo siempre la persona antes que la enfermedad, la enfermedad como circunstancias por la que atraviesa en un momento de su vida una persona, y siempre la persona, antes que nada.

Hacer un semblante del Padre César Azúa sj, cual no es fácil, sobre todo a una persona humana comprometida con su tiempo.

Durante más de 30 años nos acompañó desde la entonces Facultad de Medicina, hoy Facultad de Ciencias de la Salud, respondiendo a la integralidad de la formación del personal de salud para un mundo en constante cambio.

Recordar, que es volver a pasar por el corazón, es justo hacer un semblante de los hacedores de la Facultad, en tiempos difíciles cuando la Universidad estaba en sus comienzos y estaba afianzándose en nuestro medio.

El P. Azúa llegó a la Facultad en 1960, mostró un compromiso con su tarea pastoral que significó el camino hacia una mística en la formación de los futuros médicos y médicas.

Muchas camadas lo tuvieron como apoyo en el transitar por la facultad.

Muchas camadas encontraron en él su palabra de consuelo y de aliento.

En lo académico incorporó la "Ética Médica" al currículo del plan de estudio de la Facultad, siendo una de las primeras en incorporar esta asignatura en el plan de estudios de medicina.

Además, fue profesor de Introducción a la Filosofía, donde se sentaban las bases del marco filosófico de la enseñanza en una universidad católica de inspiración jesuita.

Hombre de Dios...

Su mirada desde la formación jesuita lo distinguió esencialmente en su trabajo, tanto como docente como sacerdote.

Fue humilde y sabio, humilde como los sabios.

Revista Methodo: Investigación Aplicada a las Ciencias Biológicas. Universidad Católica de Córdoba. Jacinto Ríos 571 Bo Gral. Paz. X5004FXS. Córdoba. Argentina. Tel.: (54) 351 4517299 / Correo: methodo@ucc.edu.ar / Web: methodo.ucc.edu.ar | SEMBLANZA Rev. Methodo 2021;6(2):109-110. 
El P. Azúa, fue un hombre de serenidad plena, juicio oportuno, criterio claro; de oración sencilla y palabra autorizada.

También, fue creador del Comité de Bioética de la Facultad y de la Clínica Universitaria Reina Fabiola, hoy es un espacio de la universidad para los temas referidos a la bioética.

Desde su llegada a Córdoba, en la Parroquia de la Sagrada Familia trabajó incansablemente en el servicio a los demás y pudo ser testigo de los hechos de violencia que enlutaron al país en esos años, llevando palabras de consuelo y acompañamiento oportuno.

En los tiempos que trabajó en la Facultad promovió permanentemente el acceso a los estudios de los que no tenían suficientes recursos para estudiar y organizó un fondo de becas con esos fines, con los aportes de los egresados que en forma anónima apoyaron la idea.

Es justo recordar las largas charlas con los/as compañeros y compañeras de trabajo, para poder responder a su preocupación de compromiso con los más desfavorecidos, organizaba lo que en aquel momento se llamaban "campamentos de trabajo" con la clara intención que la acción de los/as alumnos/as que estaban más sensibilizados dedicaran su tiempo paras apoyar obras comunitarias en zonas desfavorecidas, tanto en la ciudad de Córdoba como en el interior provincial.

Siempre movido por su espíritu de servicio que fue impregnando un modelo diferente de formación que caracteriza a la Facultad de Ciencias de la Salud hasta el día de hoy.

Esta línea de trabajo ayudó a muchos a definir el compromiso profesional futuro, de ser un profesional para los demás, anteponiendo los intereses comunitarios a los personales, creando un modelo de ejercicio profesional comprometido desde lo personal y desde lo cristiano.

Fue un hombre que se animó a soñar... soñar que los/as médicos y médicas que egresaran de la Facultad trabajaran para una sociedad más justa y al "momento de tomar decisiones, se inclinen para el bien común y no sólo para el beneficio particular"

Fue un ejemplo de inclaudicable pacifista luchador con la mirada puesta en el Evangelio y en las personas.

Entre los estudiantes él era el "Cura Azúa", el que siempre estaba, el que siempre tenía una palabra conciliadora y esperanzadora.

Fue una persona que supo ser el respaldo en el silencio que reconforta y da fuerzas para afrontar las dificultades de los estudiantes en situaciones difíciles del quehacer diario.

Por eso la Facultad tuvo el privilegio de tener un sabio entre su cuerpo de profesores.

César Azúa sj, había nacido en Labuolaye el 22 de julio de 1918 y murió en Córdoba el 19 de mayo de 1992 en un accidente de tránsito.

Prof. Cat. Mag. Carlos Emilio Gatti

(Universidad Católica de Córdoba. Facultad de Ciencias de la Salud).

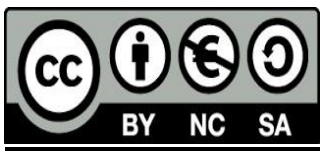

